\title{
Tangence
}

\section{La seule passion}

\section{Hélène Marcotte}

Numéro 37, septembre 1992

Autopsie du fait divers

URI : https://id.erudit.org/iderudit/025729ar

DOI : https://doi.org/10.7202/025729ar

Aller au sommaire du numéro

Éditeur(s)

Tangence

ISSN

1189-4563 (imprimé)

1710-0305 (numérique)

Découvrir la revue

Citer ce document

Marcotte, H. (1992). La seule passion. Tangence, (37), 97-100.

https://doi.org/10.7202/025729ar d'utilisation que vous pouvez consulter en ligne.

https://apropos.erudit.org/fr/usagers/politique-dutilisation/ 


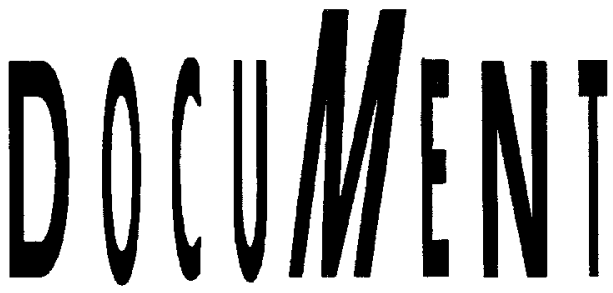

\section{La seule passion}

Hélène Marcotte

On finit par ne plus rien entendre et cela nous atteint encore

Hélène Dorion

Le monde bascule et rien ne tremble

En ta demeure

Les choses accueillent

La poussière et le temps

Les portes s'ouvrent se ferment

Tu cherches un visage encore inconnu

Pourtant si familier

Parfois tu restes dans l'ombre brisée des arbres

Tes cris ameutent les chiens errants

Le ciel se dévore

Comme une lente marée

La mort ramène la tendresse jusqu'à toi

Nous écrivons la démesure de l'oubli

Sans vraiment croire au passage du temps

Nous pillons les fictions de l'enfance

Un peu de terre s'accroche à nos pas

Le vent ramène ces mots d'amour

Que brisent les poètes

Lorsque tout s'arrête

Nos corps se cherchent une passion 
98

Tu regardes par-dessus mon épaule

Les mots changent de place

Sur la page

La colère s'écrit

Chacun quitte la scène

Côté cour

L'univers dans les bras

De tes paysages

Je ne retiens que l'écorce gravée

De l'écorce gravée

Qu'une éternité

Qui retourne à la terre

D'ici on ne distingue plus les oiseaux

Le jour s'ouvre sur une solitude

Ton absence

Il faudrait nommer la nuit

Et ses fantômes

Et la douleur qui revient

Il était une fois un visage pour l'amour Et le même pour l'averse

Or nous n'avons plus rien

Que les neiges d'antan

Et ce rire jeté

À la face du monde

Un nuage passe dans le soleil

Je t'imagine guettant l'arrêt des saisons

Le visage emmuré entre ces lignes

Que nous n'écrirons pas

Il ne t'est plus donné de choisir

Tu mets la nuit en pièces 
Et frappes le soleil d'interdit

Chacun de tes mots

Fait trembler l'horizon

Et tu marches

En posant tes mains sur les murs

Tu ne portes rien sous tes chagrins

Tu fabriques des avions en papier

Pour la suite de l'histoire

Tu revendiques les frissons et l'orage

À faire basculer les moulins à vent

Restés blottis sous l'oreiller

Tu t'inventes mille guerres

Courant l'aventure

Pour quelques anémones

Entre nous

La violence intacte

Tu peux ravir au jour

Tous les soleils qui passent

Le secret de mes nuits

N'a pas percé ton sommeil

Et tu recommences à vivre

Au matin

Sans attendre mon réveil

Chaque jour tu nais

D'un très loin obscur

La vie prend des poses

La terre creuse vers l'enfer

Je te retrouve

Sur chaque corps caressé

D'instinct

Je lève la main pour l'au revoir

Je ne sais plus rien faire d'autre 

À présent le monde est trop petit
Et le ciel trop grand
Tu tires les draps sur ta tête
Et ranges tes silences
Ta mort n'est qu'un aveu répété

Comme un passager attardé sur le quai

Le jour se roule en boule

Le sol ne retient que l'errance

La marche aride du désert

Et les chemins trop longs

Je suis maintenant

L'héroïne d'une histoire

Qui tourne tragique

Tout rentre dans l'ombre

Et je sème les cailloux

Derrière moi

Pour revenir au silence

Les mots s'entêtent à l'amour

La vie se retire

En quelques poèmes

Tu évoques les dimanches

Perdus dans les champs

Ton nom effeuillé au vent des marguerites

Tu voudrais que j'aille jusqu'à toi

Sans trembler

Mon amour

Il n'y aura plus de guerres

Plus d'échappées au cour des montagnes

La seule passion

Que nous saurons partager

Sera l'oubli 